\title{
Cholelithiasis in a patient with an anatomical variation of the cystic duct
}

Anatomical variations of the biliary tract are not uncommonly seen during routine endoscopic retrograde cholangiopancreatography (ERCP) [1 - 5].

A 91-year-old woman was evaluated for right upper abdominal colicky pain followed by jaundice. The patient denied fever, chills, dark urine or clay-colored stool. A physical examination revealed a soft abdomen with right upper quadrant tenderness and jaundice. Laboratory results indicated a cholestatic profile with elevated total bilirubin of $7.75 \mathrm{mg} / \mathrm{dL}$ (normal range: $0.10-1.20 \mathrm{mg} / \mathrm{dL}$ ), alkaline phosphatase of 198U/L (normal range: 35-105U/L), and $\gamma$-glutamyl transferase of $463 \mathrm{U} / \mathrm{L}$ (normal range: $0-38 \mathrm{U} / \mathrm{L}$ ). Abdominal ultrasound examination showed a stone-free gallbladder. The intrahepatic bile duct system was found to be normal but the extrahepatic duct system was dilated (common bile duct: $11.7 \mathrm{~mm}$ in diameter).

ERCP was indicated when abdominal computed tomography scan showed a dilated extrahepatic CBD with suspected cholangiolithiasis. During this procedure the papillary orifice was intubated. Fluoroscopy showed an 8-mm wide tubular structure leading directly to the neck of the gallbladder. After securing this duct with the guide wire on the second attempt, another, massively dilated tubular structure with barrel-shaped contrast sparings typical for extrahepatic cholangiolithiasis was opacified after intubation of a separate orifice directly beneath the first opening ( $\bullet$ Fig. 1). After this latter duct was identified as the CBD with extrahepatic cholangiolithiasis, a selective sphincterotomy was performed. After successful mechanical lithotripsy most stone fragments could be removed ( $\bullet$ Fig. 2).

With lithogenesis within the gallbladder, movement of concretions into the CBD via the normal route (e.g. cystic duct) would seem to be impossible in this case due to anatomical variations with a separate insertion of the cystic duct via a proprietary orifice at the papillary level. Therefore, by definition, in this case the extrahepatic CBD stones could be only primary bile duct stones with lithogenesis within the duct itself.

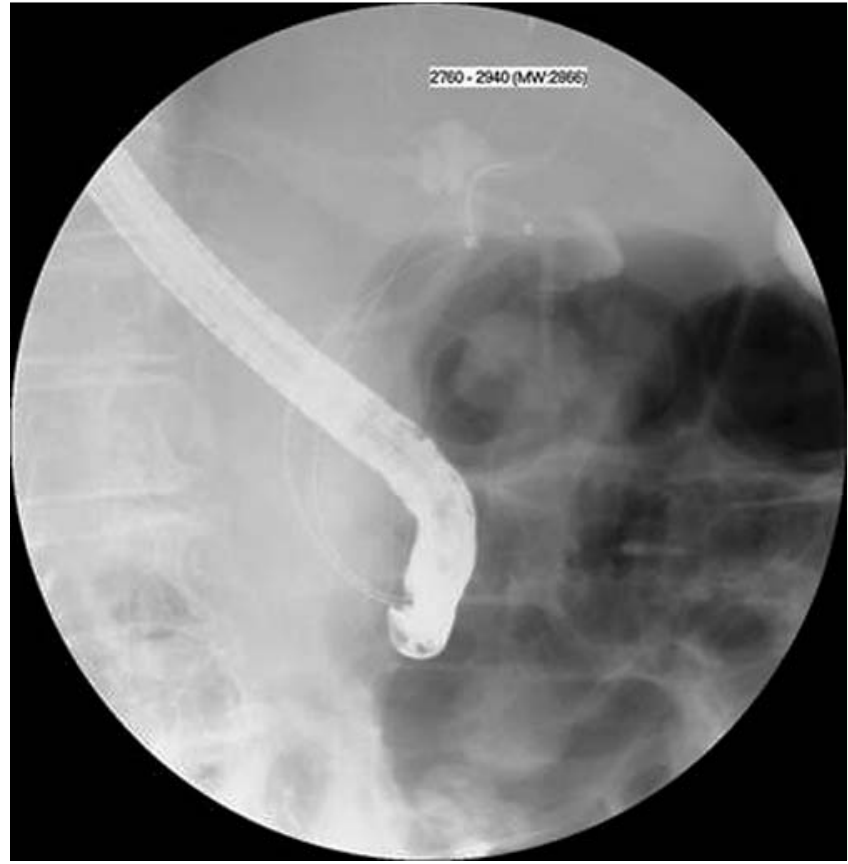

Fig. 1 A guide wire in each of the two parallel ducts.

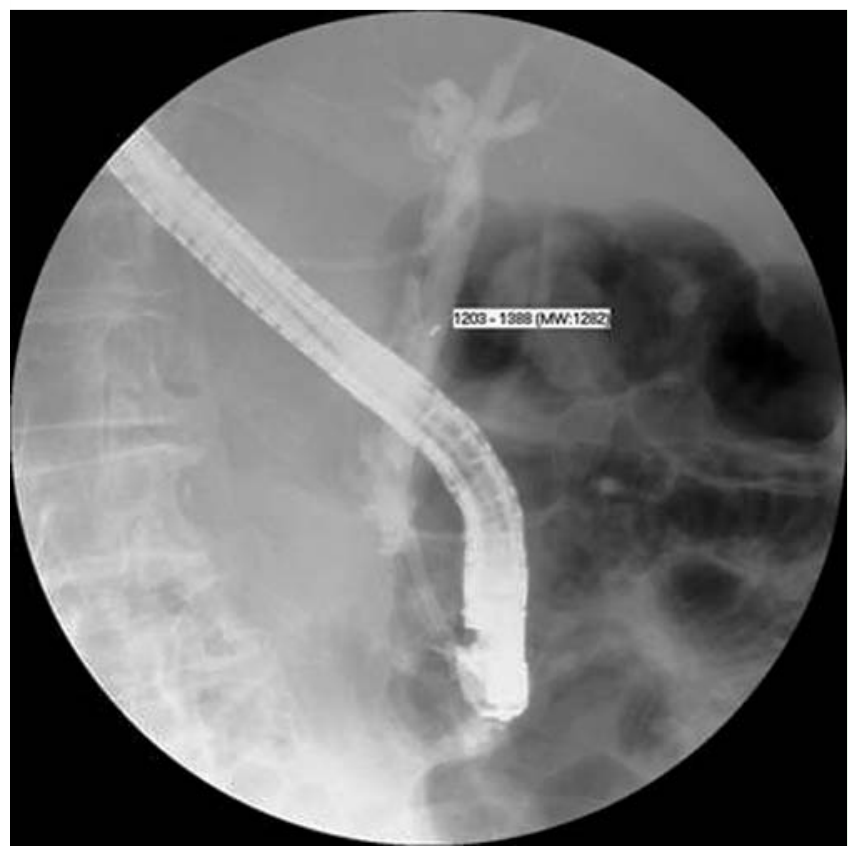

Fig. 2 A 10-Fr stent in the common bile duct with a few stone fragments remaining.

Endoscopy_UCTN_Code_CCL_1AZ_2AK

Competing interests: None

\section{F. Durchschein, F. Schreiber}

Department of Internal Medicine, Division of Gastroenterology and Hepatology, Medical University of Graz, Graz, Austria 


\section{References}

1 Rela M, Heaton ND, Karani J et al. Obstructive jaundice due to anomalous cystic duct insertion. Pediatr Surg Int 1995; 10: 159-160

2 George RA, Debnath J, Singh $K$ et al. Low insertion of a cystic duct into the common bile duct as a cause for a malpositioned biliary stent: demonstration with multidetector computed tomography. Singapore Med J 2009; 50: 243-246

3 Turner MA, Fulcher AS. The cystic duct: normal anatomy and disease processes. Radio- graphics 2001; 21: 3-22; questionnaire 288-294

$4 W u$ YH, Liu ZS, Mrikhi $R$ et al. Anatomical variations of the cystic duct: two case reports. World J Gastroenterol 2008; 14: $155-157$

5 Choi E, Byun JH, Park BJ et al. Duplication of the extrahepatic bile duct with anomalous union of the pancreaticobiliary ductal system revealed by MR cholangiopancreatography. Br J Radiol 2007; 80: e150-154

\section{Bibliography}

Dol http://dx.doi.org/

10.1055/s-0032-1309921

Endoscopy 2012; 44: E280-E281

(c) Georg Thieme Verlag KG

Stuttgart · New York

ISSN 0013-726X

\section{Corresponding author}

\section{F. Schreiber, MD}

Medical University of Graz

Auenbruggerplatz 15

A-8036 Graz

Austria

Fax: +43-316-38517108

florian.schreiber@medunigraz.at 